\title{
A Gestão e o uso racional dos Recursos Hídricos No Município de Juazeiro da Bahia
}

\author{
Manoel Faustino da Silva Junior ${ }^{1}$, Claudia Maria Lourenço da Silva ${ }^{2}$
}

\begin{abstract}
Resumo: O presente artigo tem como objetivo avaliar o uso dos recursos hídricos no município de Juazeiro da Bahia junto ao órgão responsável pela sua captação, distribuição e devolução ao meio ambiente. Para tanto, realizou-se pesquisa exploratória qualitativa através de entrevistas com gestores e técnicos de órgãos Federais, Estaduais e Municipais responsáveis pela gestão dos Recursos Hídricos no município. Os resultados permitiram observar que o órgão municipal de gestão de água, mesmo realizando novos investimentos para solucionar os problemas existentes no município e procurando trabalhar de maneira satisfatória, ainda enfrenta complexa gestão requerendo o envolvimento de vários segmentos da sociedade. Ainda, a modernização de tecnologias no interior, à exemplo de irrigação por sistema de irrigação localizada, contribui de forma expressiva para diminuir a degradação ambiental e o bom uso dos recursos hídricos.
\end{abstract}

Palavras - chave: recursos hídricos, água, meio ambiente.

\section{Management and rational use of water resources in the Juazeiro city in Bahia}

This article aims to evaluate the use of water resources in Bahia Juazeiro city from the agency responsible for their collection, distribution and return to the environment. Therefore, there was a qualitative exploratory research through interviews with managers and technicians of Federal agencies, State and Municipal responsible for managing the water resources in the municipality. Results showed that the municipal body of water management, even making new investments to solve the existing problems in the city and looking for work satisfactorily, still faces complex management requiring the involvement of various segments of society. Still, the modernization of technology within, eg irrigation by drip irrigation system, contributes significantly to reduce environmental degradation and the proper use of water resources.

Keywords: water resources, water, environment.

\section{Introdução}

A humanidade presencia constantes fatos relacionados ao ecossistema planetário, a qual envolve principalmente a fauna e a flora. Fatos esses divulgados quase que diariamente pela mídia. Atualmente a preocupação volta-se para outro setor do meio-ambiente: os recursos hídricos, devido à escassez, conflitos e a contaminação dos mananciais usados pelo homem.

\footnotetext{
${ }^{1}$ Discente do curso de Pós-graduação (Lato Sensu) em Gestão Pública Municipal da Universidade Federal do Vale do São Francisco Univasf. e-mail: m.faustino.junior@bol.com.br;

${ }^{2}$ Professora orientadora do curso de Pós-graduação (Lato Sensu) em Gestão Pública Municipal da Univasf.

E-mail: claudialourenco71@gmail.com;
} 
Id on Line Revista Multidisciplinar e de Psicologia

Id on Line Multidisciplinary Journal and Psycology

Segundo Tundisi (2014), a água é recurso renovável essencial à vida no planeta terra. Esse mesmo autor relata que seu ciclo tem continuado por séculos e milênios, sustentando a biodiversidade e mantendo em funcionamento ciclos nos ecossistemas, comunidades e populações. É considerado um bem econômico, porque é finita, vulnerável e essencial para a conservação da vida e do meio ambiente.

No entanto, sua escassez impede o desenvolvimento de diversas regiões (BORSOI e TORRES, 1997) e seu uso indiscriminado promove uma forma de degradação ambiental. Ainda, segundo Tundisi (2008), especialistas afirmam que a crise da água no século XXI é muito mais de gerenciamento do que uma crise real de escassez e estresse. A expansão das cidades através de novos investimentos e projetos irrigados para agroindústria, verdadeiras indústrias na zona rural, tem contribuindo para o agravamento e a complexidade da crise da água. A escassez gera conflitos, fato registrado na bacia do rio Salitre.

Historicamente, a Bacia do Rio Salitre é marcada pelo conflito do uso da água. Esse rio Salitre pertence à Bacia do Rio São Francisco. De acordo com Pinheiro e Carvalho (2010), na referida bacia os conflitos foram amenizados, tendo desaparecido totalmente em algumas situações, porque os usuários em situações de perenes conflitos passaram a reconhecer e procurar a autoridade detentora do poder outorgante para mediar e solucionar o problema.

A água consumida na agricultura é de cerca de 70\% da disponibilidade total. (COELHO, et al., 2005) Há uma enorme necessidade de redução desse uso com a introdução de tecnologias adequadas, eliminação dos desperdícios e introdução de reuso e reciclagem (TUNDISI, 2008). O Brasil, com 14\% da água do planeta, possui, entretanto, uma distribuição desigual do volume e disponibilidade de recursos hídricos: enquanto um habitante do Amazonas tem $700.000 \mathrm{~m} 3$ de água por ano disponível, um habitante da Região Metropolitana de São Paulo tem 280 m3 por ano disponível (Tundisi, 2008).

Pesquisas e estudos contribuem para que novas tecnologias modernizem os projetos irrigados, essas tecnologias proporcionam ao homem do campo o uso racional dos recursos hídricos. Quanto às transposições, mais especificamente a transposição do Rio São Francisco, é importante considerar que somente um projeto conjunto de revitalização do rio (e despoluição) e um grande projeto de desenvolvimento regional poderão ser a base para a transposição (Tundisi et al., 2008). Alterações climáticas terão papel relevante no ciclo hidrológico e na quantidade e qualidade da água. Essas alterações podem promover inúmeras mudanças na disponibilidade de água e na saúde da população humana. (TUNDISI, 2008).

À medida que aumentam os efeitos da degradação ambiental sobre a disponibilidade de recursos hídricos, a gestão de bacias hidrográficas assume crescente importância no Brasil. Ocorrem importantes avanços no setor de recursos hídricos ao longo dos últimos vinte anos, sendo que o mais 
Id on Line Revista Multidisciplinar e de Psicologia

Id on Line Multidisciplinary Journal and Psycology

significativo é a mudança de uma gestão institucionalmente fragmentada para uma legislação integrada e descentralizada, principalmente com a edição da Lei Federal n. 9.433, em 8 de janeiro de 1997 (BRASIL, 2007), e a criação da Agência Nacional de Águas (ANA), em 2000. A questão que mais salta aos olhos é a necessidade de uma crescente articulação das políticas de recursos hídricos, no contexto de políticas socioambientais, com todas as esferas do governo (JACOBI e BARBI, 2007).

As relações entre Estado e sociedade civil, como espaço de construção de alianças e cooperação são traspassadas por conflitos que se originam do impacto das assimetrias sociais e de seus impactos no meio ambiente e das formas de resistência, organização e participação dos diversos atores envolvidos (JACOBI e BARBI, 2007). Dentro desta perspectiva de governança, no Brasil existem instrumentos de participação previstos na Constituição, tais como o projeto de lei de iniciativa popular, o referendo e o plebiscito. Além desses instrumentos, a Constituição prevê outros meios de participação, como é o caso dos conselhos comunitários, onde representantes da população podem participar de decisões nos campos da educação, saúde, direitos da criança e do adolescente, meio ambiente e as audiências públicas, onde a população deve ser informada e ouvida sobre projetos e iniciativas do Legislativo e do Executivo, ou sobre decisões que este deve tomar (JACOBI e BARBI, 2007).

Outro fator preponderante se dá pela falta de capacidade gerencial em áreas urbanas e deve ser considerado outro problema fundamental na gestão: a maioria dos municípios não possui estrutura para o planejamento e o gerenciamento dos complexos processos dos recursos hídricos nas áreas urbanas (TUNDISI, 2014). Ainda, outro aspecto a destacar é o papel das redes, como um importante instrumento de cooperação que possibilita um avanço nas relações horizontais entre atores territorialmente identificados, e dinamizados no segmento da sociedade civil, estimulando a capacitação dos seus representantes (JACOBI e BARBI, 2007). A questão que mais salta aos olhos é a necessidade de uma crescente articulação das políticas de recursos hídricos, no contexto de políticas socioambientais, com todas as esferas do governo.

O município de Juazeiro da Bahia, situado no norte do estado, a margem direita do rio São Francisco na região do semiárido brasileiro, é um município que, de acordo com dados do IBGE (2015), que possui 218.324 mil habitantes, sendo considerada uma cidade de porte médio, possui uma área territorial que corresponde a 6.500,691 km2. É uma cidade cuja economia baseia-se na agricultura irrigada, cidade com rico potencial cultural, com teatro, cinema e universidades particulares, estadual e federal. A responsabilidade pela qualidade e portabilidade da água, no município de Juazeiro-Bahia, para consumo humano é do Serviço Autônomo de Água e Esgoto (SAAE), é uma Autarquia municipal criada pela lei $\mathrm{n}^{\circ} 565$ de 23 junho de 1965, para exercer com exclusividade todas as atividades administrativas e técnicas que se relacionem com os serviços públicos de água e esgoto, ao qual se 
Id on Line Revista Multidisciplinar e de Psicologia

Id on Line Multidisciplinary Journal and Psycology

inclui a captação, tratamento, distribuição e a devolução dos recursos hídricos ao meio-ambiente. Os projetos que o SAAE realiza baseiam-se nas normas da Lei Federal 9433/97 Art. $1^{\circ}$ incisos 1, 11, 111, 1V, V, Vl (BRASIL, 1997), seguindo a Portaria 2914/2011do Ministério da Saúde (BRASIL 2011), ao qual, através de tabelas, determina a qualidade da água.

As informações sobre a gestão sustentável e projetos associados aos recursos hídricos, tanto para a utilização da água no consumo humano, quanto para a o agronegócio são poucas, havendo, portanto, a necessidade de levantamentos sobre os mecanismos de gestão.

Desta forma, no presente trabalho encontram-se informações acerca da gestão das bacias citadas, bem como uma investigação da forma de uso dos recursos hídricos, desde sua exploração até sua distribuição, identificação dos problemas em relação à captação e fornecimento dos mesmos no município de Juazeiro - Bahia. A pesquisa é baseada na informação obtida através de órgãos e instituições relacionadas aos recursos hídricos do município.

\section{Material e Métodos}

A presente pesquisa foi realizada no município de Juazeiro, localizado no estado da Bahia, no período dos meses de Abril e maio 2016. Foram realizadas entrevistas com gestores e técnicos de órgãos Federais, Estaduais e Municipais responsáveis pela gestão dos Recursos Hídricos no município de Juazeiro - BA. As informações coletadas têm os seguintes focos: a gestão da água utilizada no consumo humano, com informações coletadas no Serviço de Autônomo de Água e Esgoto (SAAE), a fiscalização do uso de recursos hídricos no município de Juazeiro por parte do Instituto do Meio Ambiente e Recursos Hídricos (INEMA), e a gestão de Irrigação por parte da Companhia de Desenvolvimento no Vale do São Francisco e Parnaíba (CODEVASF), especificamente no perímetro irrigado de maniçoba.

Para a obtenção dos resultados, realizou-se pesquisa exploratória qualitativa, onde os entrevistados seguindo-se a metodologia descrita por Révillion (2003), adotando-se uma postura flexível e não formalizada, com livre manifestação de opinião dos entrevistados. Os questionamentos foram não padronizados e direcionados para o desempenho das atribuições de cada entrevistado em seu respectivo órgão.

Os resultados foram apresentados através de uma sequência narrativa, conforme descrição de Alves e Silva (1992), com ancoragem em literatura e nas próprias verbalizações dos sujeitos entrevistados e tomando-se o cuidado de elaboração de uma redação coerente e fluida que encaminhe o leitor para a compreensão, análise e crítica do texto. 
Id on Line Revista Multidisciplinar e de Psicologia

Id on Line Multidisciplinary Journal and Psycology

\section{Resultados e Discussão}

\section{Águas destinadas ao consumo humano}

Segundo o entrevistado Antônio Pedro do Nascimento, assessor de comunicação do Serviço Autônomo de Água e Esgoto (SAAE), as etapas realizadas para recebimento, tratamento e distribuição de água para consumo humano na cidade de Juazeiro - BA são as seguintes:

\section{a) Sistema de captação de água:}

Em relação à água destinada ao consumo humano, a água utilizada para abastecimento é captada do Rio São Francisco, numa vazão de 679 litros de água bruta por segundo. A captação é feita por redes de tubulação em PVC até a estação de tratamento (ETA).

A água bruta que chega a ETA é tratada com sulfato de alumínio, hidróxido de cálcio, hipoclorito de sódio e flúor. Estes reagentes estão de acordo com a portaria $n^{\circ} 2.914$ de 12 de dezembro de 2011, do Ministério da saúde. Essa portaria dispõe sobre os procedimentos de controle de vigilância da qualidade da água para consumo humano e seu padrão de potabilidade. São realizadas análises físico-químicas e bacteriológicas em todas as fases do processo, ao qual são encaminhadas ao centro de controle operacional, com valores bem abaixo do que determina o inciso primeiro da referida portaria, correspondendo a $5 \%$ dos valores permitidos de turbidez.

É ressaltado que o limite máximo de turbidez para qualquer amostra pontual deve ser de 5,0 uT, em toda a extensão do sistema de distribuição (reservatório de rede). As amostras pontuais do SAAE estão com registros de 2,0 uT, abaixo do valor máximo permitido.

Em relação, Estação de Tratamento de Água (ETA) possui além dos tanques decantadores, 24 filtros e dois grandes reservatórios subterrâneos. A captação trabalha 24 horas com quatro potentes conjuntos moto-bomba, tendo um flutuante visando o aumento da eficiência do sistema. Ao ser questionado sobre a outorga da água por parte do referido órgão para a realização das atividades, o entrevistado relata que existe contrato para concessão do uso da água junto a Agência Nacional de Águas (ANA), com vigência até o final de 2017, com mensalidade de R \$32.124,10 pelo uso dos recursos hídricos na cidade.

\section{b) Sistema de abastecimento e distribuição de água}

Ao todo são distribuídos $2.500 \mathrm{~m} 3 / \mathrm{h}$ de água. São 58.760 ligações oficiais na sede e 13.119 nos distritos. $\mathrm{O}$ entrevistado relata que o grande problema enfrentado pela instituição são as ligações clandestinas que correspondem a $20 \%$ do total de abastecimento em todo o município. 
Id on Line Revista Multidisciplinar e de Psicologia

Id on Line Multidisciplinary Journal and Psycology

\section{c) Sistema de esgoto}

O sistema de esgotamento sanitário de juazeiro atende a mais de 130.000 habitantes num percentual de $65 \%$ de cobertura. Existem 20 estações elevatórias, com previsão de $95 \%$ de saneamento ao final do ano de 2017.

O esgoto coletado é aduzido até as estações elevatórias e posteriormente às quatro lagoas de estabilização, onde recebe o devido tratamento. A manutenção diária dos mais de $210.000 \mathrm{~m}$ de rede coletora de esgoto é feita por funcionários e caminhões hidrojateadores.

$\mathrm{O}$ entrevistado relata que o sistema de esgotamento visa à preservação e diminuição dos impactos ambientais e ao oferecimento de melhor qualidade de vida à população. A rede está sendo ampliada através da construção da Estação de Tratamento de Esgoto (ETE), que tem como principal objetivo acompanhar o crescimento da cidade.

Finalmente, o entrevistado informa índices importantes associados à gestão da água no município, conforme tabela a seguir.

Tabela 1. Gestão do uso dos recursos hídricos no município de Juazeiro-BA.

\begin{tabular}{ll}
\hline INDICADORES & INDICES \\
\hline Qualidade dos serviços & Satisfatória* \\
Geração de empregos diretos & 310 postos \\
Geração de empregos indiretos & Não contabilizado (terceirização de serviços) \\
Volume de água captada $\left(\mathrm{m}^{3}\right)$ & $2.576 \mathrm{~m}^{3}$ de água/h \\
Volume de água fornecida $\left(\mathrm{m}^{3}\right)$ & $2.530 \mathrm{~m}^{3}$ de água/h \\
Perdas na distribuição d'água $(\%)$ & $20 \%$ \\
Receita atual gerada & Não informado
\end{tabular}

O Serviço Autônomo de Água e Esgoto (SAAE) cumpre as exigências determinada pelo Ministério da Saúde (MS), onde os reagentes estão de acordo com a portaria $\mathrm{n}^{\circ} 2.914$ de 12 de dezembro de 2011. Outro ponto é em relação à turbidez da água, onde o limite máximo permitido para amostra é de 5,0 uT de acordo com o Ministério da Saúde (MS). O Serviço Autônomo de Água e Esgoto (SAAE) as amostras pontuais são de 2,0 uT abaixo do valor máximo permitido. Através dos citados processos visando os procedimentos de controle de vigilância da qualidade da água para consumo humano e seu padrão de potabilidade, medidas importantes para alcançar índices satisfatórios em relação aos seus serviços junto aos seus usuários. 
O Serviço Autônomo de Água e Esgoto (SAAE) conta com no seu quadro funcional com 310 empregados diretos. Ainda, de acordo com o entrevistado o citado orago conta com empregos indiretos que fica a cargo de prestadoras de serviços, sendo que o mesmo não soube informar os números de empregados.

O volume de água bruta captada junto ao rio São Francisco 679 litros por segundo que corresponde a $2.576 \mathrm{~m}^{3}$ de água/h e são distribuídos 670 litros por segundo a população correspondendo a $2.530 \mathrm{~m}^{3}$ de água/h.

As perdas na distribuição da água, na sua maior parte estão ligadas as ligações clandestinas, algo em torno de $20 \%$. Em relação à receita atual o entrevistado não soube informar, devido não estar com os dados atualizados. Segundo o entrevistado a inadimplência corresponde a $25 \%$ gerando um déficit nas receitas do citado órgão. Atualmente são atendidas com abastecimento de água no município de Juazeiro - Bahia mais de 230 mil habitantes, sendo que 58.760 ligações são na sede e 13.119 no interior totalizando 71.879 ligações. As despesas com a manutenção e os investimentos não foram informadas.

As informações passadas pelo entrevistado mostram um ponto de extrema importância: a água para consumo humano em Juazeiro é tratada com sulfato de alumínio, hidróxido de cálcio, hipoclorito de sódio e flúor. Segundo Dempsey, citado por Lopes (2014), à exceção do flúor, os demais compostos são coagulantes empregados com o objetivo de diminuir as forças que mantém separadas as partículas em suspensão na água, desestabilizando-as, podendo assim agregar-se a outras partículas (RITCHER, 2009). As informações denotam que os compostos utilizados na água tratada para consumo da população de Juazeiro estão dentro das especificações legais, dentro legislação vigente, bem como das especificações técnicas citadas em literatura. As concentrações de flúor não foram informadas. Porém, segundo Frazão et al. (2011), o Valor máximo Permitido (VMP) é de 1,5mg F/L.

A portaria 1.469 do Ministério da Saúde, que estabelece o controle e a vigilância da qualidade da água para o consumo humano e seu padrão de potabilidade exigiu a adequação das instituições ou órgãos para o cumprimento da norma classifica os tipos de sistemas de abastecimento de água em: sistema coletivo, que se constitui de uma instalação composta por um conjunto de obras civis, materiais e equipamentos, destinados à produção e à distribuição canalizada de água potável para as populações, sob a responsabilidade do poder público, mesmo que administrada em regime de concessão ou permissão; e sistema ou solução alternativa de abastecimento de água - que se constitui de toda modalidade de abastecimento coletivo de água, distinta do sistema coletivo, incluindo, por exemplo, fontes, poços comunitários, distribuição por veículo transportador, instalações condominiais horizontais e verticais (FREITAS e FREITAS, 2005). 
Id on Line Revista Multidisciplinar e de Psicologia

Id on Line Multidisciplinary Journal and Psycology

De acordo com Freitas e Freitas, entre as exigências, a amostragem frequente da potabilidade deve ser feita. Segundo o entrevistado, as amostragens são feitas e a vigilância e controle são feitas pelo Ministério da Saúde e o órgão ambiental do estado da Bahia: Instituto do Meio Ambiente e Recursos Hídricos (INEMA)/BA.

\section{Captação e uso dos recursos em Juazeiro}

Segundo o analista ambiental Paulo Henrique Braga Ribeiro, do Instituto do Meio Ambiente e Recursos Hídricos (INEMA)/BA, a maior parte dos recursos hídricos utilizados pelo SAAE é captada da bacia hidrográfica do rio São Francisco, com autorização outorgada pela Agencia Nacional das Águas (ANA). Em algumas localidades do interior do município a captação dos recursos hídricos se dá através de rios estaduais e poços artesianos, que é realizada em parceria com empresas privadas e Companhia de Engenharia Ambiental e Recursos Hídricos da Bahia (CERB).

No caso dos rios estaduais e perfuração de poços, a outorga é autorizada junto ao INEMA. O órgão exerce a função de fiscalizar os recursos hídricos e o meio ambiente através de elaboração de planos diretores das bacias hidrográficas, onde são definidas as vazões de referencia dos rios, em relação às vazões máximas outorgadas.

Como exemplo, ele referencia que $100 \mathrm{~m} / \mathrm{s}=20 \%$ da vazão do rio que poderá ser utilizada. Após analise da viabilidade do empreendimento, condicionante para o uso da água, essas ações evitam a degradação ambiental e conflitos armados.

A outorga á direito de uso dos recursos hídricos: o usuário recebe a autorização, ou concessão, ou ainda permissão para fazer uso da água. Com esta outorga pretende-se que o usuário racionalize o uso dos recursos hídricos. Ainda, de acordo com Paulo Henrique, o SAAE apresentou ao Instituto do Meio Ambiente e Recursos Hídricos (INEMA)/BA o projeto onde foi observado que faltava conclusão, inclusive estabelecendo prazos ao que além do monitoramento de qualidade: $1^{\circ}$ Efluentes brutos; $2^{\circ}$ Efluentes tratados e $3^{\circ}$ Efluentes do rio São Francisco antes e depois do recebimento desses efluentes.

\section{Tecnologia do sistema de irrigação}

Segundo o gerente executivo do Distrito de Irrigação do projeto de Irrigação Mandacaru (DIM), Valter Matias de Alencar, o projeto possui 626 lotes com uma área irrigável de 8.458,62 ha, 
Id on Line Revista Multidisciplinar e de Psicologia

Id on Line Multidisciplinary Journal and Psycology

com captação com volume máximo de $21.600 \mathrm{~m} 3 / \mathrm{h}$. A irrigação localizada, que funciona através do sistema de gotejamento, é citada pelo entrevistado como um método eficiente para o uso da água. Ele conceitua a eficiência de irrigação como a relação entre a quantidade de água requerida pela cultura e a quantidade utilizada.

Diante de um quadro de escassez de recursos hídricos que vivem a humanidade, e por Juazeiro/BA estar localizada em uma região onde o problema de água é conflitante, faz-se necessário a buscar por políticas abrangentes, que envolva a sociedade civil em processos de consulta e decisórios na gestão da água. O sistema de irrigação localizada por gotejamento proporciona uma economia de $30 \%$ a $50 \%$ da água, além do crescimento de produtividade em até $200 \%$, além da economia com mão de obra, energia e produtos (PEDROSO, 2015).

$\mathrm{Na}$ informação obtida através da entrevista com o gerente executivo do projeto Mandacaru, é possível observar que o emprego do sistema de gotejamento é feito justamente para aumentar a eficiência no uso da água de irrigação e aumento da economia de água.

\section{Conclusão}

Diante do exposto, foi possível a obtenção de informações que ocorreram através da pesquisa junto à Autarquia Pública Municipal que, ao qual se configura como o gestor responsável pelos recursos hídricos no município de Juazeiro - Bahia que é Serviço Autônomo de Água e Esgoto (SAAE). O referido órgão promove ações junto à sociedade, através de suas equipes do setor social e meio ambiente, onde são realizadas reuniões e palestras educacionais com intuito de conscientizar a população quanto ao uso racional da água.

A complexidade em relação à gestão dos recursos hídricos ainda é um desafio para a gestão pública municipal por envolver vários segmentos da sociedade. Este trabalho procurou relatar os problemas e as soluções ao qual o citado órgão enfrenta. O Serviço Autônomo de Água e Esgoto (SAAE) de Juazeiro - Bahia procura trabalhar de maneira satisfatória e responsável junto a toda população dentro da lei vigente e obedecendo as normas estabelecidas pelo órgão fiscalizador.

O SAAE realiza novos investimentos para solucionar os problemas existentes no município de Juazeiro - Bahia. Como também procura acompanhar o avanço urbano, existindo uma preocupação em relação à gestão dos recursos hídricos e ao meio ambiente, tanto na sede como no interior no que visa melhorar relação homem e natureza. Exemplos dessas ações são os investimentos na área de saneamento básico que já atende mais de 130 mil habitantes num percentual de $65 \%$ de cobertura. Além da construção de 20 estações elevatórias e das ligações domiciliares e infra-domiciliares. O 
Id on Line Revista Multidisciplinar e de Psicologia

Id on Line Multidisciplinary Journal and Psycology

Serviço Autônomo de Água e Esgoto (SAAE), objetivo com o final da obra que o município ficará com 95\% de esgoto coletado e tratado. Mas, para a realização de novos investimentos no município de Juazeiro - Bahia o referido órgão submete os projetos a uma analise técnica junto ao órgão fiscalizador que no caso de Juazeiro - Bahia é Instituto do Meio Ambiente e Recursos Hídricos (INEMA). Após analise do projeto o técnico responsável emite parecer, em caso de positivo é liberada o certificado de licença ambiental, em caso de alguma irregularidade no projeto são determinadas condicionantes necessárias sugeridas pelo técnico do INEMA.

A modernização de tecnologias no interior, mais precisamente na área irrigada, contribui de forma expressiva para diminuir a degradação ambiental e o bom uso dos recursos hídricos. O Distrito de Irrigação de Maniçoba (DIM) é um exemplo que através de investimentos em novas tecnologias proporciona ao agricultor mais produtividade e a diminuição dos impactos ambientais, ao qual é utilizado o sistema de irrigação localizada por gotejamento.

As dificuldades que o Serviço Autônomo de Água e Esgoto (SAAE) enfrenta ocorrem, principalmente, junto aos seus usuários, onde foi observado um índice que corresponde a $20 \%$ de ligações clandestinas. A falta de esgotamento sanitário em algumas localidades é outro problema ser solucionado, pois certas ligações residenciais de esgoto utilizam riachos como lagoas de decantação ao qual é um problema social, ambiental e de saúde pública.

A falta de esgotamento também pode provocar doenças transmitidas por meio de recursos hídricos ou pelo contato com o esgoto. A falta de planejamento de gestões anteriores gerou um déficit que existe no município em relação ao saneamento básico e a rede de esgotamento sanitário que, ao longo do tempo, não acompanhou o seu crescimento habitacional e é um dos entraves a serem superados pelo referido órgão.

A realização de um trabalho de conscientização do órgão junto à população, processo esse que ocorre através tem de campanhas educacionais, tem como objetivo informar a importância dos recursos hídricos para a sobrevivência das varias espécies no meio ambiente. Como resultado, poderá ocorrer à redução do desperdício de água no município de Juazeiro - Bahia. Um ponto positivo em relação ao SAAE são os investimentos que estão sendo realizados principalmente em relação à coleta e a devolução do esgoto sanitário ao rio São Francisco, ao qual ocorre após o processo de tratamento nas lagoas de estabilização, gerando água de qualidade para devolver ao meio ambiente.

Ainda, as informações obtidas permitiram constatar que houve um avanço em relação às políticas públicas implementadas pelo SAAE. Por exemplo, os investimentos no sistema de captação, tratamento, distribuição e devolução da água ao meio ambiente. Outro ponto é o saneamento básico e o esgotamento sanitário, onde o citado órgão busca acompanhar o avanço urbano, com o objetivo de proporcionar melhor qualidade de vida a população. 
Id on Line Revista Multidisciplinar e de Psicologia

Id on Line Multidisciplinary Journal and Psycology

\section{Referências}

ALVES, Z.M.M. B; SILVA, M.H.G.F.D. da. Análise qualitativa de dados de entrevista: Uma proposta. Paidéia. . v.2. p. 61-69. 1992.

BRASIL. LEI $\mathbf{N}^{\mathbf{0}} \mathbf{9 . 4 3 3}$, DE 8 DE JANEIRO DE 1997. Disponível em: http://www.mma.gov.br/port/conama/legiabre.cfm?codlegi=370. Acesso em: 10/04/2016.

BRASIL. PORTARIA $\mathbf{N}^{\mathbf{2}} \mathbf{2 . 9 1 4}$, DE 12 DE DEZEMBRO DE 2011. Disponível em: ttp://bvsms.saude.gov.br/bvs/saudelegis/gm/2011/prt2914_12_12_2011.html. Acesso em: 10/04/2016.

BORSOI Z, M. F.; TORRES, S. D. A. A política de recursos hídricos no Brasil. Revista do BNDES. 15p. 1997. Disponível em: http://rash.apanela.com/tf/IEEE/rev806.pdf. Acesso em: 10/04/2016.

COELHO, E. F; FILHO, M. A. C; OLIVEIRA, S. Agricultura irrigada: e de uso de água eficiência de irrigação. Bahia Agricultura. v. 7 n.1. p. 57-60. 2005. Disponível em: http://www4.seagri.ba.gov.br/pdf/socioeconomia4_v7n1.pdf. Acesso em: 20/05/2016.

FREITAS, M. B; FREITAS, C. M. A vigilância da qualidade da água para consumo humano desafios e perspectivas para o Sistema Único de Saúde. Ciência Saúde Coletiva. v.10, n.4. p. 9931004. 2005.

INSTITUTO BRASILEIRO DE GEOGRAFIA E ESTATISTICA. CIDADES. In: IBGE. Senso 2012. Disponível em http://www.cidades.ibge.gov.br/xtras/temas. php?lang $=\&$ codmun $=291840 \&$ idtema $=117 \&$ search=bahia|juazeiro|ensino-matriculas-docentes-e-redeescolar-2012. Acesso em 22/04/2016.

JACOBI, P.R.; BARBI, F. Democracia e participação na gestão dos recursos hídricos no Brasil. Katálysis. v. 10 n. 2 p. 237-244. 2007.

LOPES, B.V. Eficiência de Coagulantes na Remoção de Diferentes Concentrações de Ferro e Manganês para ETA Terras Baixas. Trabalho Conclusão de Curso. Universidade Federal de Pelotas. Pelotas. 52p. Il. 2014.

PEDROSO, D. Irrigação por gotejamento aumenta produtividade nos canaviais. 2015. Disponível em: http://www.setorenergetico.com.br/entrevistas-artigos/artigo-irrigacao-por-gotejamento-aumentaprodutividade-nos-canaviais/9127/. Acesso em: 10/06/2016.

PINHEIRO, J. C. V.; CARVALHO, R. M. Gestão dos recursos hídricos no sistema agroindustrial nordestino: uma abordagem teórica. Revista Brasileira de Gestão e Desenvolvimento Regional. v. 6 n. 1 p. 52-72. 2010. Disponível em: http://rbgdr.net/revista/index.php/rbgdr/article/view/261/177 Acesso em: 18/05/2016

RITCHER, C. A. Água: Métodos e tecnologia de tratamento de agua. São Paulo. Blucher, 2009.

RÉVILLION, A.S.P. A Utilização de Pesquisas Exploratórias na Área de Marketing. Revista Interdisciplinar de Marketing. v.2, n.2, p. 21-37. 2003.

TUNDISI, J.G. Recursos hídricos no Brasil: problemas, desafios e estratégias para o futuro. coord. 76p. Il. 2014. Disponível em: http://www.abc.org.br/IMG/pdf/doc-5923.pdf. Acesso em: 10/04/2016. 
TUNDISI, J.G. Recursos hídricos no futuro: problemas e soluções. Estudos avançados. v. 22. n. 63. p. 7-16. 2008.

\section{Como citar este artigo (Formato ABNT):}

SILVA JÚNIOR, M.F.; SILVA, C.M.L. A Gestão e o uso racional dos recursos hídricos no Município de Juazeiro da Bahia. Id on Line Revista Multidisciplinar e de Psicologia, Julho de 2016, vol.10, n.30, Supl 3, p.48-59. ISSN 1981-1179.

Recebido: 12/07/2016

Aceito:13/07/2016 